\title{
PARCERIAS NO TERCEIRO SETOR: ALGUMAS CONTRIBUIÇÕES DA LITERATURA CIENTÍFICA NACIONAL E INTERNACIONAL
}

\section{PARTNERSHIPS IN THE THIRD SECTOR: SOME CONTRIBUTIONS OF NATIONAL AND INTERNATIONAL SCIENTIFIC LITERATURE}

Lucas Borges Kappel UNIUBE - Universidade de Uberaba / UFU - Universidade Federal de Uberlândia / IFTM Instituto Federal do Triângulo Mineiro lucaskappel@yahoo.com.br

João Paulo Seno Universidade de Uberaba / UFU jpseno@uol.com.br

Edileusa Godói de Sousa Universidade de Uberaba / UFU edileusagodoi@uol.com.br

Submissão: $14 / 03 / 2016$ Aprovação: 18/10/2017 


\title{
RESUMO
}

Esse artigo objetivou estudar as contribuições práticas de estudos do Terceiro Setor, ou seja, as parcerias que podem ser estabelecidas com o setor público e privado a fim de sugerir ações semelhantes para os gestores sociais. Apesar de estudos já terem sido desenvolvidos sobre o tema, pouco foi levantado acerca das contribuições e aplicações práticas destes estudos para os gestores dessas organizações. Foi realizada revisão bibliográfica, o levantamento dessas contribuições, a categorização das mesmas e posteriores análises. Os principais resultados apontaram para 97 contribuições práticas à gestão das organizações sociais, uma vez que podem ser utilizadas por outras instituições do setor. A partir dessas contribuições, foram sugeridas ações baseadas nas categorias a seguir, a fim de auxiliar os gestores sociais: oportunidades, desafios, críticas, cidadãs, legais e econômicas. Ao final, ainda, foram propostos parâmetros de análise contemporâneos com a finalidade de permear destas relações de parceria entre as organizações dos três setores citados.

Palavras-Chave: Terceiro Setor. Parceria. Contribuições práticas.

\begin{abstract}
This article aims to study the practical contributions of studies of the Third Sector, that is, the partnerships that can be established with the public and private sectors, in order to suggest similar actions for social managers. Although these studies have already been developed on the subject, little has been done about the contributions and practical applications of these studies to the managers of these organizations. Was conducted a literature review, the survey of these contributions, the categorization of these and subsequent analyzes. The main results showed 97 practical contributions to the management of social organizations, since they can be used by other institutions of the sector. From these contributions, actions based on the following categories were suggested to social managers: opportunities, challenges, critics, citizens, legal and economic. In the end, though, have been proposed analysis parameters contemporaries in order to permeate these partnership relationships among the organizations of the three sectors mentioned.
\end{abstract}

Keywords: Third Sector. Partnership. Practical Contributions. 


\section{INTRODUÇÃO}

Nos últimos anos tem-se verificado aumento nos estudos relativos ao Terceiro Setor, ou ainda, ao Empreendedorismo Social, no Brasil. Neste contexto, o empreendedor social é o agente ativo na geração de ações que causam o impacto local, buscando sempre o objetivo coletivo (OLIVEIRA, 2016).

O aumento desses estudos pode estar ligado à popularização dos termos supracitados que, apesar de terem chegado ao país apenas na década de 1990, já eram representados na prática pelas organizações não governamentais - ONGS (CALEGARE; SILVA JÚNIOR, 2009). Outro fato que também pode ser o desencadeador de tal crescimento nos estudos é a constante necessidade de profissionalizar as organizações desse setor, característica observada, na maioria das vezes, apenas em organizações privadas, conforme já discutido por Bose e Godói-de-Sousa (2012).

Juntamente a essa característica, a priori pertencente a organizações privadas, outras se fizeram necessárias a fim de garantir a sobrevivência desses empreendimentos, "transitando entre um modelo assistencialista e/ou reivindicatório para outro voltado para a autossustentação" (BOSE; GODÓI-DE-SOUSA, 2012, p. 9). Outra característica observada no setor privado e que possa ser transportada às organizações do terceiro setor seria as parcerias com outras instituições. Estas poderiam se dar também com o Terceiro Setor ou empresas sociais, denominação que predomina internacionalmente.

As parcerias, das quais as organizações do Terceiro Setor conseguem recursos para sua sobrevivência, são celebradas conforme contratos estabelecidos com instituições da iniciativa privada e/ou pública, regidos e regulados pela Lei $\mathrm{N}^{\circ} 9.790$, de 23 de março de 1999 (LIMA FILHO, 2010) e influenciados por outras legislações, como a Lei $\mathrm{N}^{\circ}$ 9.637, de 15 de maio de 1998, o Decreto $N^{\circ} 3.100$, de 30 de junho de 1999 (FERNANDES, 2004) e a Lei $\mathrm{N}^{\circ}$ 11.079, de 30 de dezembro de 2004 (GUTIERRES, 2007).

Alguns autores estudaram tais parcerias com o setor público, ou primeiro setor (GODÓI-DE-SOUSA; VALADÃO JÚNIOR, 2011; PERRET et al., 2009; KNIPHOFF; NAZZARI; OLIVEIRA, 2006; LIMA FILHO, 2010; GUTIERRES, 2007; OLIVEIRA; ENGLER, 2009; ALMEIDA; PRAÇA, 2009; FISCHER; FALCONER, 1998; CARVALHO, 2010; QUEIROZ, 2010; FERNANDES, 2004), outros as estudaram com organizações privadas (LOPES; BALDI, 2009; MONTE; CARVALHO, 2005), outros ainda, estudaram as relações de parcerias entre os três setores (GARCIA; SALES, 1999; GORNI; DREHER; MACHADO, 2009; PERONI et al., 2009) e, também, há aqueles estudos que em que apenas essas parcerias fizeram parte dos dados obtidos com o estudo (SILVA et al., 2009). Uma tentativa de realização de estudos sobre as parcerias do terceiro setor foi feita por Stefani et al. (2012). Sem aprofundar as contribuições práticas relacionadas às parcerias ao Terceiro Setor, e utilizando-se de um período de tempo determinado, tais autores realizaram uma revisão bibliográfica de 10 anos (2001-2011) em algumas revistas previamente selecionadas, com busca no título, usando os termos Redes, Rede Social e Parcerias. Com o objetivo de estudar como o tema é abordado, a sua evolução ao longo do período e as relações entre os autores e as revistas, foi identificado que a produção nacional é "formada por alguns subgrupos coesos, que se organizam em torno de uma revista e de universidades próximas a ela" (STEFANI et al., 2012, p. 18). Em sua maioria, esses autores utilizaram, qualitativamente, de estudos de caso, de revisões bibliográficas, de ensaios teóricos, bibliometrias e discussões acerca dos termos, considerando a aplicabilidade dos mesmos em alguma organização específica.

Apesar de esses estudos vislumbrarem os termos, discutirem o tema e exemplificarem, em alguns casos, como determinada instituição do Terceiro Setor promove suas relações de parcerias, pouco foi levantado acerca das contribuições e aplicações práticas destes estudos para os gestores destas organizações. 
Diante disso, e levando-se em consideração as parcerias de organizações do Terceiro Setor, em relação às organizações dos três setores, este artigo procurou levantar e categorizar as principais contribuições dos estudos já realizados, a fim de sugerir ações aos gestores e propor parâmetros de análise para ajudar a entender a atualidade. Essas escolhas se deram pelo fato de a lacuna teórica apontada permitir uma aproximação da academia com os praticantes. Dessa forma este estudo atende às necessidades da sociedade em geral, uma vez que se trata de instituições criadas pela sociedade em prol do desenvolvimento e da dignidade da própria sociedade (CALEGARE; SILVA JÚNIOR, 2009).

Este artigo encontra-se estruturado da seguinte maneira, a partir desta introdução: a segunda seção, o referencial teórico, aborda os estudos já realizados acerca das parcerias do terceiro setor e suas principais ligações com os objetivos deste; a terceira seção apresenta os aspectos metodológicos; em seguida, a quarta seção consta da apresentação e análise dos resultados; na quinta seção foram feitas as considerações finais; em seguida, estão listadas as referências utilizadas no estudo.

\section{REFERENCIAL TEÓRICO}

O estabelecimento de redes organizacionais intersetoriais é o caminho para se construir uma nova realidade social, pois viabiliza o processo de execução de políticas públicas eficazes a partir do trabalho integrado entre os diversos setores envolvidos (JUNQUEIRA, 2008). Na definição idealizada de Martinho (2001), uma rede entre organizações é definida pela existência de valores e objetivos compartilhados, autonomia entre os membros, descentralização do poder e a existência de múltiplos níveis decisórios.

Para este trabalho, definem-se tais redes, ou parcerias, como um acordo formal de cooperação que tenha clareza de propósitos, criação de valor social, transparência e comprometimento entre as partes (GODÓI-DE-SOUSA; VALADÃO JÚNIOR, 2011), colocando as organizações do Terceiro Setor como elemento central e comum, conforme apresentado na Figura 1.

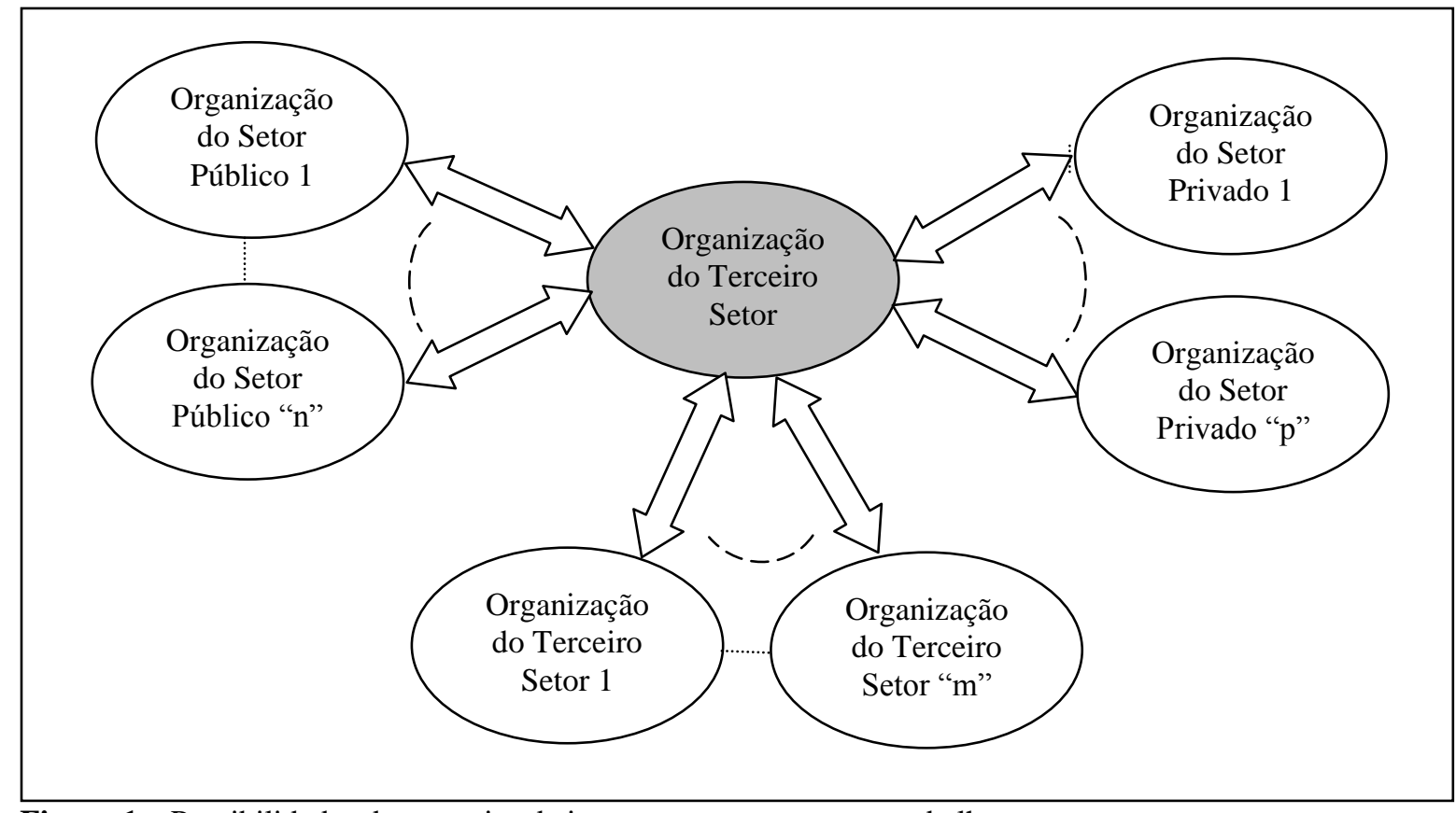

Figura 1 - Possibilidades de parcerias de interesse para o presente trabalho.

Fonte: Elaborada pelos autores. 
Admite-se, como mostra a Figura 1, que interações simultâneas podem ser estabelecidas, ou seja, as organizações do Terceiro Setor podem estabelecer parcerias com o Setor Público, com o Setor Privado e com organizações do próprio Terceiro Setor. É possível, então, estabelecer uma rede complexa de relacionamentos.

Apesar das diferenças semânticas, os termos parceria, redes de cooperação e alianças estratégicas serão utilizados como sinônimos no transcorrer do texto, com as conotações de parceria, compartilhamento e cooperação nas relações intersetoriais e interorganizacionais.

\subsection{As razões que levam às parcerias}

Godói-de-Sousa e Valadão Júnior (2011) afirmam que há consenso em reconhecer que parcerias são estabelecidas quando duas ou mais organizações decidem trabalhar juntas para perseguir um objetivo comum e que este relacionamento deve ser conveniente para todos, com as parcelas de responsabilidades, ônus (incluindo riscos) e benefícios adequadamente distribuídos entre elas.

As parcerias estabelecidas pelo governo têm sido a melhor maneira de minimizar, no curto e médio prazo, a incapacidade do Estado em prover bens e serviços públicos de qualidade e são uma oportunidade (e desejo das organizações do Terceiro Setor) para influenciar mudanças nas políticas públicas (GODÓI-DE-SOUSA; VALADÃO JÚNIOR, 2011).

Godói-de-Sousa e Valadão Júnior (2011) afirmam ainda, que as relações de parceria estabelecidas pelas organizações do Terceiro Setor são uma forma de buscar a sustentabilidade (econômica), pois essas organizações têm dificuldades em gerar suas próprias receitas e são vulneráveis às fortes oscilações das fontes de renda tradicionais. Este parece ser o maior desafio dessas organizações, quando se analisam os aspectos econômicos enquanto a dimensão humana expõe o desafio da colaboração (GODÓI-DE-SOUSA, 2005). Nesse sentido, Tesche (1999) identificou, num estudo realizado com agricultores do nordeste, que o motivo inicial para a organização em grupos foi a busca de interesses econômicos, mas as relações de reciprocidade, que originaram e viabilizaram a consolidação da rede, geraram outros benefícios, ligados aos valores humanos, fundamentais para a resistência, sobrevivência e desenvolvimento das unidades familiares.

Para Prates (2009) as parcerias são de fundamental importância para que a comunidade tenha algum sucesso coletivo para conseguir bens públicos, ou seja, tenha conexões com atores do Setor Público para conseguir que problemas de infraestrutura sejam resolvidos, serviços estejam disponíveis ou equipamentos sejam instalados.

Lopes e Baldi (2009) buscam explicações para a formação de redes e destacam que os adeptos da teoria dos jogos têm dado destaque à cooperação em suas análises; a economia dos custos de transação considera que as alianças e redes são adotadas para reduzir os custos; no campo da estratégia, as alianças são consideradas uma forma enfrentar ameaças e capitalizar oportunidades; e numa visão sociológica, sugere-se que as redes são mais do que estruturas de adaptação e cooperação, são tomadores de decisão socialmente construídos que conquistam legitimidade e passam a ser copiadas ao longo do tempo. Os autores citam ainda, a abordagem da aprendizagem, que justifica a formação de alianças pela oportunidade de aprendizagem que ela traz à organização.

Para Perret et al. (2009), as parcerias e redes sociais surgem como formas viáveis para colocar em prática a gestão de ações sociais públicas realizadas não exclusivamente pelo Estado, mas pela cooperação entre Estado, sociedade civil e iniciativa privada, ao que os autores chamam de gestão social. Segundo estes autores, a formação de parcerias e as redes sociais desempenham um papel fundamental na articulação do poder e na busca do 
compromisso com as mudanças (descentralização do poder) para alterar práticas e integrar ações que favorecem a inclusão social e a melhoria da qualidade de vida de parcela da população.

Para Junqueira (2008), as organizações se articulam em redes sociais para inovar e criar, de maneira dinâmica, a realidade social que, cada vez mais, se torna complexa.

Pelo exposto, parece que a motivação econômica tem sido predominantemente a razão para a formação de redes, mas a interação entre os atores envolvidos tem efeitos em muitas outras dimensões, como a troca de conhecimento e melhoria na gestão.

\subsection{A natureza das relações entre os setores}

Godói-de-Sousa (2005) realizou um estudo extensivo a respeito das possibilidades de relacionamento entre os setores, chamadas de redes intersetoriais, cujas fronteiras não são bem definidas, pois algumas organizações são típicas de determinado setor, enquanto outras compartilham algumas características de mais de um. Ao analisar tais relacionamentos, a autora cita Thompson (1997, p. 46), que afirma: "As empresas focam sua ação na obtenção do lucro, os governos buscam novas formas de poder, ao passo que as ONGs devem focar sua ação nas pessoas como centro do cenário social". Estes aspectos são considerados desafios para as relações entre setores.

De forma condensada, para Godói-de-Sousa (2005) o relacionamento entre o Terceiro Setor e o Setor Público pode se dar de diversas maneiras, dependendo do projeto político que sustenta a relação, o poder efetivo de cada uma das partes e o grau de empenho das pessoas envolvidas. As relações podem ser muito próximas das ideais ou sofrer distorções. Para alguns autores, o Estado tem mais poder e essa assimetria gera inevitavelmente distorções no relacionamento. Também, a partir do trabalho da autora, tem-se que o relacionamento entre o Terceiro Setor e o Setor Privado, é problemático, muitas vezes contraditório e mesmo divergente, devido às diferenças de pensamento entre os dois tipos de organização. Para que os relacionamentos deem certo, é preciso que não haja imposição de vontade entre as partes, que o Setor Público não pense em terceirização nem o Setor Privado pense nos ganhos mercadológicos, mas todos pensem nos seres humanos que serão beneficiados. Lembrando Junqueira (2008), trabalhar em rede não significa mera substituição, mas complementação e articulação, certa autonomia das partes e controle.

As parcerias envolvendo os três setores, simultaneamente (o Público, o Privado e o Terceiro Setor), são pouco frequentes, apesar da proliferação de discursos de apoio às alianças intersetoriais, entre governos e sociedade civil e entre organizações do Terceiro setor e o mercado. Além disso, existe a visão de que estes arranjos podem ser uma alternativa viável para enfrentar as novas demandas sociais (BRONZO; TEODÓSIO; ROCHA, 2012). Há exemplos de sucesso, que demonstram a viabilidade das parcerias intersetoriais, como o caso da ASMARE (Associação dos Catadores de Papel, Papelão e Material Reaproveitável de Belo Horizonte), descrito por Silva et al. (2009), onde as ações resultantes do processo decisório são operacionalizadas por redes estratégicas entre atores empresariais e públicos para a efetivação dos empreendimentos.

Bronzo, Teodósio e Rocha (2012) afirmam que há riscos e possibilidades que podem emergir do encontro entre atores da sociedade civil, do estado e do mercado. Os autores citam associações não legitimadas, barreiras geradas pela assimetria de poder e ações que, paradoxalmente, atrapalham a modernização das relações, mas foram criadas para melhorar a gestão das políticas sociais e projetos intersetoriais, como as práticas de prestação de contas, característica do ambiente público e que têm resultado num afastamento entre as organizações e o público servido pelos projetos e políticas sociais. A respeito das possibilidades, os autores citam as novas formas de relacionamento que podem surgir da interação entre três setores, a 
união e complementaridade de competências e recursos, a melhoria na efetividade e impacto das intervenções nos problemas sociais, a corresponsabilidade, mais informação e capacidade de previsão de riscos sociais e aprendizado compartilhado. Há, ainda, os resultados indesejáveis deste relacionamento, como o surgimento de discursos com motivações populistas, ideológicas, econômicas ou comerciais, que levariam a uma materialização dos relacionamentos de parceria causando, por sua vez, desconfiança mútua, rejeições e posturas defensivas entre os atores envolvidos. (BRONZO; TEODÓSIO; ROCHA, 2012).

Percebe-se que as diferentes características como valores, objetivos e lógica dominante de cada setor, podem gerar desafios à interação, mas também podem ser fonte de oportunidades e inovações na busca de soluções para os problemas sociais.

\section{ASPECTOS METODOLÓGICOS}

Quanto à abordagem, este trabalho foi pautado em uma pesquisa qualitativa que, segundo Bauer e Gaskell (2011), não tem a intenção de contar opiniões, mas de verificar nas diferentes opiniões aspectos e representações sobre o assunto; essa pesquisa "evita números, lida com interpretações das realidades sociais" (BAUER; GASKELL, 2011, p. 23).

A natureza do trabalho é aplicada, devido a seu próprio objetivo, uma vez que, segundo Barros e Lehfeld (2000), nesse tipo de pesquisa há a intenção de aplicar os resultados teóricos obtidos na prática.

Em relação aos objetivos, trata-se de uma pesquisa descritiva que, conforme explicita Vergara (2005), demonstra as características de determinada população ou de determinado fenômeno sem ter o compromisso de explicá-los, apesar de servir de base para este fato.

Em se tratando da fonte de dados, utilizou-se de uma revisão bibliográfica, a qual tem a finalidade de proporcionar ao cientista o encontro com a teoria já existente; tal procedimento pode gerar aprimoramento do conhecimento com consequentes contribuições ao tema (GIL, 2007). Quanto à técnica de análise, fez-se uso da análise de conteúdo que, embora culmine em descrições numéricas de características, possui fortes resultados qualitativos, uma vez que aproxima e categoriza informações mais praticadas e importantes para o alcance dos objetivos outrora estabelecidos (BAUER; GASKELL, 2011). Além disso, foi realizada a análise de documentos, os quais foram compreendidos por leis, decretos e literatura cinzenta (notícias, pesquisas de organizações do terceiro setor e documentos oriundos de trabalhos).

Os procedimentos para a realização deste estudo foram divididos em seis fases distintas: Na primeira, por intermédio do Google scholar, buscou-se artigos relacionados às palavras-chave Parceria e Terceiro Setor ou Aliança e Terceiro setor, estes em português, e às palavras-chave Partnership e Third Sector ou Alliance e Third Sector, estes em língua inglesa, todas refinadas pelo título dos trabalhos. As buscas nacionais ocorreram no dia 22/10/2012 e resultaram em 25 trabalhos; nas buscas internacionais, realizadas no dia 10/11/2012, foram encontrados 42 trabalhos. Na segunda fase foram selecionados 13 trabalhos nacionais e 9 internacionais; tais trabalhos são aqueles que explicitavam reais contribuições práticas às parcerias do Terceiro Setor, tais como lições, ensinamentos e dificuldades. Foram ainda, acrescidos cinco estudos nacionais, localizados de maneira diferente destes já citados, por terem sido considerados importantes e por se tratarem do tema proposto. Em síntese, a análise dos trabalhos se deu conforme exposição do Quadro 1: 


\begin{tabular}{|c|c|c|c|}
\hline \multicolumn{4}{|c|}{ Quadro 1 - Distribuição dos trabalhos analisados } \\
\hline Origem da publicação & Forma de publicação & Quantidade & Totais \\
\hline Nacionais & $\begin{array}{c}\text { Periódicos } \\
\text { Congressos, seminários e afins } \\
\text { Dissertações }\end{array}$ & $\begin{array}{c}12 \\
4 \\
2\end{array}$ & 18 \\
\hline Internacionais & $\begin{array}{c}\text { Periódicos } \\
\text { Congressos, seminários e afins } \\
\text { Dissertações }\end{array}$ & $\begin{array}{l}6 \\
2 \\
1 \\
\end{array}$ & 9 \\
\hline \multicolumn{2}{|c|}{ Total } & \multicolumn{2}{|c|}{27} \\
\hline
\end{tabular}

Fonte: Elaborado pelos autores com base na revisão bibliográfica.

Na terceira fase do trabalho foram apresentadas as 97 contribuições às parcerias do terceiro setor, por meio da elaboração de dois quadros, um com estudos nacionais e outro com estudos internacionais, de modo a facilitar seus entendimentos para os empreendedores sociais, já que eles atuam diretamente em ações que causem o impacto local (OLIVEIRA, 2016). Procurou-se, entretanto, trabalhar estas contribuições de maneira a abarcar o caráter científico das mesmas a fim de manter a sua relevância acadêmica e social. Em uma quarta fase, as contribuições foram separadas e divididas em categorias, de modo a facilitar a análise dos resultados.

$\mathrm{Na}$ quinta fase do estudo, mediante a junção das categorias criadas e das contribuições observadas, foram sugeridas ações aos gestores sociais, as quais se acredita podem minimizar entraves e maximizar benefícios; na sexta e última fase foram propostos parâmetros de análise de parcerias entre as organizações dos três setores, chamados aqui de contemporâneos, levando-se em consideração todas as informações coletadas e os resultados alcançados.

Como limitações para este estudo, por se tratar de uma interpretação de resultados, podem ser citadas a possibilidade de haver equívocos nas interpretações das contribuições; tal limitação foi atenuada com a observação de vários outros trabalhos e resultados e categorização dos mesmos, com entendimentos comuns. Outra possível limitação se refere ao fato de que as instituições possuem realidades diferentes e, assim, as sugestões aos gestores sociais, aqui expostas, podem não se aplicar a todas. Outro fator que pode ser citado como uma limitação é a possibilidade da existência de trabalhos relevantes, com a titulação diferente da proposta neste estudo; atenuou-se tal limitação com a análise de alguns outros trabalhos, conforme anteriormente mencionado, que possuíam palavras-chave diferentes e, mesmo assim, eram relevantes para a análise.

\section{APRESENTAÇÃO E ANÁLISE DOS DADOS}

Após a realização de tais procedimentos os dados levantados foram analisados e o resumo dessa análise segue nesta seção; cabe aqui destacar que as contribuições observadas nos trabalhos analisados não se esgotam neste estudo por terem aplicações amplas e poderem ser verificadas mediante a realidade de cada instituição e sob a ótica de cada objetivo de estudo.

\subsection{Contribuições práticas às parcerias do terceiro setor}

Nesta etapa os trabalhos foram divididos em relação aos periódicos, aos congressos, seminários e afins, e dissertações, justamente para proporcionar uma análise mais detalhada de cada estudo. As contribuições foram ainda numeradas, a fim de facilitar a sua consulta quando de sua citação às categorias. 
No Quadro 2 podem-se verificar os estudos nacionais analisados, dos quais foram retiradas as contribuições práticas às instituições do Terceiro Setor:

\section{Quadro 2 - Trabalhos nacionais analisados e suas contribuições ao Terceiro Setor} (continua)

\begin{tabular}{|c|c|}
\hline Autores & Demais Informações \\
\hline \multicolumn{2}{|r|}{ Periódicos } \\
\hline $\begin{array}{l}\text { Garcia e Sales } \\
\quad(1999)\end{array}$ & $\begin{array}{l}1 \text { - As parcerias podem ocorrer por complementaridade, suplementaridade, alinhamento ou } \\
\text { substituição. } \\
2 \text { - São condições para se estabelecer uma parceria: estruturais, institucionais, políticas, } \\
\text { econômicas, sociais, culturais e históricas. }\end{array}$ \\
\hline $\begin{array}{l}\text { Fernandes } \\
\quad(2004)\end{array}$ & $\begin{array}{l}3 \text { - As parcerias tendem a promover a substituição de uma administração pública } \\
\text { burocrático-hierárquica por uma administração pública gerencial. } \\
4 \text { - Para a realização de parcerias com instituições já estabilizadas, o estado terá a difícil } \\
\text { missão de apresentar padrões de desempenho compatíveis com as novas exigências destas } \\
\text { organizações da sociedade civil. } \\
5 \text { - O Governo pode agir em parceria com instituições da sociedade civil para fomentar a } \\
\text { renovação e o desenvolvimento da comunidade. } \\
6 \text { - A associação entre Estado e sociedade se sustenta, em suma, no respeito ao senso de que } \\
\text { o ente estatal - o "grupo maior" - deve admitir e incitar a capacidade produtiva e distributiva } \\
\text { das instituições organizadas pela sociedade - "grupos menores" - seja em razão de } \\
\text { retratarem estes, mais fidedignamente, os anseios da comunidade que eles representam e da } \\
\text { qual estão mais próximos, seja em virtude do próprio reconhecimento, pelo ente público, da } \\
\text { impossibilidade de, sozinho, fazer frente a todas as necessidades que lhe são apresentadas. } \\
7 \text { - Em meios jurídicos a parceria abrange todas as formas de sociedade que, sem formar } \\
\text { uma nova pessoa jurídica, são organizadas para a consecução de fins de interesse público. } \\
8 \text { - Há quem acredite que as parcerias são efetivadas pelo estado como forma de evitar a } \\
\text { privatização de instituições, enquanto para outros, elas inibem a iniciativa particular. } \\
9 \text { - Lei N }{ }^{\circ} 9.637 \text {, de } 15 \text { de maio de } 1998 \text {, estabelece a definição de contrato de gestão entre o } \\
\text { poder público e a entidade qualificada como organização social. } \\
10 \text { - Decreto № } 3.100 \text {, de } 30 \text { de junho de } 1999 \text {, que dita que a parceria pode ser estabelecida } \\
\text { segundo concurso de projeto, porém, não necessariamente. } \\
11 \text { - A execução do termo de parceria deve ser acompanhada e fiscalizada pelo órgão do } \\
\text { poder público da área de atuação correspondente à atividade fomentada, e pelos conselhos de } \\
\text { políticas públicas das áreas correspondentes de atuação existentes, em cada nível de governo. }\end{array}$ \\
\hline $\begin{array}{l}\text { Monte e } \\
\text { Carvalho } \\
(2005)\end{array}$ & $\begin{array}{l}12 \text { - As relações de parceria entre as ONGs e as empresas promovem colaboração, } \\
\text { cooperação e auxílio, capaz de proporcionar às parceiras benefícios mútuos. } \\
13 \text { - Estabelecer uma parceria é agir estrategicamente, visando obter resultados específicos. } \\
14 \text { - As parcerias neste trabalho caracterizaram-se, preferencialmente, pelo repasse de } \\
\text { recursos financeiros da empresa para a ONG. } \\
15 \text { - As empresas não detêm o conhecimento acerca da aplicação dos recursos, pois o que } \\
\text { importa é a imagem que a ONG tem na mídia e na sociedade e que pode ser associada, } \\
\text { vantajosamente, à empresa. } \\
16 \text { - As ONGs, em razão da sua dependência financeira, acatam a vontade e imposições das } \\
\text { empresas com certa naturalidade. } \\
17 \text { - As ONGs não influenciam as ações das empresas a ponto de alterar suas prioridades em } \\
\text { suas atividades empresariais. } \\
18 \text { - Em resumo, às ONGs, há a necessidade de diminuir os problemas sociais e, nas } \\
\text { empresas, a de obter legitimidade. }\end{array}$ \\
\hline $\begin{array}{l}\text { Kniphoff, } \\
\text { Nazzari e } \\
\text { Oliveira (2006) }\end{array}$ & $\begin{array}{l}19 \text { - A adaptação de novas metodologias e as parcerias com a sociedade civil, estados e } \\
\text { empresas é fundamental para o sucesso de qualquer projeto que vise à inclusão social. }\end{array}$ \\
\hline
\end{tabular}




\begin{tabular}{|c|c|}
\hline Autores & Demais Informações \\
\hline \multicolumn{2}{|r|}{ Periódicos } \\
\hline $\begin{array}{l}\text { Peroni et al. } \\
\qquad(2009)\end{array}$ & $\begin{array}{l}20 \text { - A parceria entre o público e o privado acaba sendo "a política" pública. } \\
21 \text { - As parcerias entre organizações públicas e do Terceiro Setor legitimam a perda dos } \\
\text { direitos sociais. } \\
22 \text { - Com tais parcerias sobram poucos espaços para a participação da sociedade civil na } \\
\text { definição, formulação e implantação das políticas públicas sociais, uma vez que } \\
\text { normalmente tais parcerias se reforçam em objetivos locais e pré-determinados. } \\
23 \text { - Como o estado não consegue implantar tais políticas públicas, o Terceiro Setor são as } \\
\text { possíveis saídas para os graves problemas sociais. } \\
24 \text { - Tais parcerias podem significar a substituição do estado enquanto promotor das ações } \\
\text { sociais, uma vez que gradativamente já vem repassando a "competência" para o público "não } \\
\text { estatal". } \\
25 \text { - As parcerias, às vistas do estado, funcionam como não responsabilização da execução } \\
\text { da política social. } \\
26 \text { - Tal parceria coloca limites ainda à democracia, uma vez que no caso estudado toda a } \\
\text { comunidade escolar teve suas tarefas determinadas pela instituição do Terceiro Setor. }\end{array}$ \\
\hline $\begin{array}{c}\text { Almeida e } \\
\text { Praça (2009) }\end{array}$ & $\begin{array}{l}27 \text { - A participação do Terceiro Setor junto à rede pública de atenção à saúde gerou um } \\
\text { movimento na sociedade, que se constituiu em uma nova forma de intervenção social; tal } \\
\text { fórmula contribuiu para a redução da transmissão vertical do HIV. }\end{array}$ \\
\hline $\begin{array}{l}\text { Silva et al. } \\
\text { (2009) }\end{array}$ & $\begin{array}{l}28 \text { - Para a realização das atividades e manutenção da estrutura da organização, as parcerias } \\
\text { podem ser efetivadas com o Governo, com órgãos internacionais, com empresas da iniciativa } \\
\text { privada e com outras organizações da sociedade civil organizada. } \\
29 \text { - A construção das parcerias se deu a partir da cadeia produtiva. }\end{array}$ \\
\hline $\begin{array}{l}\text { Lopes e Baldi } \\
\quad(2009)\end{array}$ & $\begin{array}{l}30 \text { - Faz-se necessário, imprescindível e natural que as organizações se apresentem em } \\
\text { parcerias, independente da natureza destas. } \\
31 \text { - O contexto social emergente de alianças anteriores e considerações de interdependência } \\
\text { estratégica influencia as decisões de parcerias entre firmas. }\end{array}$ \\
\hline $\begin{array}{c}\text { Oliveira e } \\
\text { Engler (2009) }\end{array}$ & $\begin{array}{l}32 \text { - A parceria visa assumir a posição de complementaridade da cidadania, promovendo } \\
\text { benefícios à população na área de saúde, educação, assistência social, meio ambiente, entre } \\
\text { outros. } \\
33 \text { - Visa uma ação conjunta em prol da democracia, equidade e desenvolvimento; trata-se } \\
\text { da experimentaçâo de novos modos de pensar e agir sobre a realidade social. }\end{array}$ \\
\hline $\begin{array}{l}\text { Gorni, Dreher e } \\
\text { Machado } \\
\quad(2009)\end{array}$ & $\begin{array}{l}34 \text { - As parcerias desempenham importante papel em diversos setores da economia, entre } \\
\text { eles, a atividade turística. } \\
35 \text { - Com as parcerias as organizações promovem melhores formas de comercialização, } \\
\text { novos meios de captação de recursos e melhoria no atendimento das necessidades sociais. } \\
36 \text { - Quando da realização das parcerias, além da necessidade de ter uma identidade } \\
\text { organizacional bem definida, faz-se necessário estar preparada para partilhar seus valores e } \\
\text { respeitar reciprocamente às responsabilidades de cada uma. } \\
37 \text { - Aos se estabelecer as parcerias, as partes devem levantar seus pontos em comum, como } \\
\text { missão e visão, a fim de revelar ao outro o grau de compatibilidade e de integração. } \\
38 \text { - Quando da efetivação de uma parceria, os integrantes devem realizar campanhas de } \\
\text { marketing de forma integrada e reunindo recursos dos participantes, ao invés de competirem. } \\
39 \text { - É preciso evitar que a cooperação seja utilizada a fim de atender a interesses pessoais, e } \\
\text { que um elemento exerça sobre o(s) outro(s) seu poder político e/ou financeiro. } \\
40 \text { - Para a consolidação das parcerias faz-se fundamental o envolvimento dos integrantes. } \\
41 \text { - As parcerias devem ter objetivos concretos e metas a serem alcançadas definidas, para } \\
\text { que seu progresso possa ser medido. } \\
42 \text { - A falta de envolvimento pode comprometer a eficiência das parcerias e até mesmo } \\
\text { impossibilitar a adesão de novos participantes. } \\
43 \text { - As parcerias intersetoriais constituem em um importante fator para o desenvolvimento } \\
\text { turístico às localidades. }\end{array}$ \\
\hline$(2010)$ & $\begin{array}{l}44 \text { - Sugere-se à organização a nomeação de pelo menos um responsável pela administração } \\
\text { dos recursos recebidos, a fim de garantir a transparência e a lisura no recebimento de tais } \\
\text { recursos provenientes do Governo. }\end{array}$ \\
\hline
\end{tabular}




\begin{tabular}{|c|c|}
\hline Autores & Demais Informações \\
\hline \multicolumn{2}{|r|}{ Periódicos } \\
\hline $\begin{array}{l}\text { Godói-de- } \\
\text { Sousa e } \\
\text { Valadão Júnior } \\
\quad(2011)\end{array}$ & $\begin{array}{l}45 \text { - A ONG se "apoiou" no fato da "prestação de serviços", a qual realizava, ser de } \\
\text { competência do governo e, assim, realizou-se a parceria. } \\
46 \text { - Necessidade de aliar as orientações de desenvolvimento; enquanto para o Governo é o } \\
\text { mercado, para a ONG é o social. } \\
47 \text { - A aliança entre ONG e Governo configura-se em uma estratégia de terceirização por } \\
\text { parte do segundo. } \\
48 \text { - O "controle" das operações acaba por ficar no Governo, uma vez que o mesmo é o } \\
\text { principal mantenedor da instituição. }\end{array}$ \\
\hline \multicolumn{2}{|r|}{ Congressos, Seminários e Afins } \\
\hline $\begin{array}{l}\text { Fischer e } \\
\text { Falconer } \\
(1998)\end{array}$ & $\begin{array}{l}49 \text { - Há o reconhecimento do estado, quanto ao seu insucesso nas práticas sociais, quando há } \\
\text { o estabelecimento de parcerias com as ONGs. } \\
50 \text { - Com os recursos oriundos de parcerias, as instituições do Terceiro Setor podem } \\
\text { conseguir apoio gerencial e técnico quando da realização de suas atividades. } \\
51 \text { - Faz-se necessário o estabelecimento de indicadores a fim de medir o desempenho das } \\
\text { ações pautadas nas parcerias. } \\
52 \text { - Nem sempre as parcerias são os caminhos mais indicados, uma vez que deve ser levado } \\
\text { em consideração o momento histórico e institucional vivido. }\end{array}$ \\
\hline & $\begin{array}{l}53 \text { - Consideração da parceria como um instrumento de modernização gerencial da gestão } \\
\text { pública, de forma mais eficaz e eficiente. } \\
54 \text { - Lei N } N^{\circ} 11.079 \text {, de } 30 \text { de dezembro de } 2004 \text {, a qual institui normas para as licitações e } \\
\text { contratações de parcerias entre o setor privado e a administração pública. } \\
55 \text { - As parcerias entre o Terceiro Setor e o Governo tendem a "profissionalizar" o setor } \\
\text { público, de forma a estabelecer padrões de desempenho. } \\
56 \text { - A legislação tende a favorecer as parcerias entre o Terceiro Setor e o governo, e tais } \\
\text { parcerias tendem a promover o "ganha-ganha" } \\
57 \text { - As organizações sociais vêm assumindo demandas de políticas sociais ou vêm } \\
\text { influenciando as políticas públicas. }\end{array}$ \\
\hline $\begin{array}{l}\text { Perret et al. } \\
\quad(2009)\end{array}$ & $\begin{array}{l}58 \text { - As parcerias são formas viáveis de se praticar e dar eficiência à gestão social. } \\
59 \text { - As redes sociais são avanços de entendimento em relação às parcerias de maneira mais } \\
\text { ágil e menos formalizada. } \\
60 \text { - Os desafios às parcerias são da evolução da caridade para a cidadania, da ação } \\
\text { individual para a coletiva e da ação pontual para uma ação gerencial. } \\
61 \text { - O próprio governo tem promovido tentativas de gerar novas parcerias, como por } \\
\text { intermédio do Programa Comunidade Solidária do Governo Federal. } \\
62 \text { - Existem três forças que norteiam as parcerias, sendo elas as forças políticas, } \\
\text { econômicas e sociais. } \\
63 \text { - As parcerias promovem a relação "ganha-ganha", na qual todos os envolvidos obtém } \\
\text { retorno. } \\
64 \text { - Problemas em parcerias: baixo envolvimento, falta de confiança e compartilhamento de } \\
\text { valores, diferenças operacionais, dependência e/ou modificações na sua forma de atuar, por } \\
\text { intermédio da influência. } \\
65 \text { - As parcerias são sistemas de aprendizado recíproco que permitem a construção de } \\
\text { permanentes conhecimentos, ações e reformulações. } \\
66 \text { - Promovem articulação de múltiplos saberes, experiências e poderes. } \\
67 \text { - Tendem a promover descentralização e intersetorialidade. } \\
68 \text { - As parcerias são fundamentais para a articulação do poder, inclusão social e melhoria } \\
\text { da qualidade de vida de parcela da população. }\end{array}$ \\
\hline $\begin{array}{l}\text { Stefani et al. } \\
\text { (2012) }\end{array}$ & $\begin{array}{l}69 \text { - Verificação de que os estudos acerca de redes e parcerias são maiores a cada ano, fato } \\
\text { que pode demonstrar aumento da profissionalização das organizações do setor e da } \\
\text { relevância do tema para a academia. }\end{array}$ \\
\hline
\end{tabular}


(conclusão)

\begin{tabular}{|c|c|}
\hline Autores & Demais Informações \\
\hline & Dissertações \\
\hline Carvalho & $\begin{array}{l}70 \text { - Nas parcerias entre Governo e Terceiro Setor evidencia-se a influência e adoção da } \\
\text { atitude mais gerencial e menos assistencialista, sob a justificativa de maximizar os recursos } \\
\text { provenientes das fontes de financiamento governamental e privado. } \\
71 \text { - As parcerias buscam soluções mais eficazes na implementação de políticas sociais. } \\
72 \text { - As parcerias representam uma via de mão dupla, na qual há a troca de recursos pela } \\
\text { execução de atividades específicas. } \\
73 \text { - Faz-se necessário escolher instituições, para que se realizem parcerias, segundo alguns } \\
\text { critérios como: objetivos comuns, compatibilidade atuação local, experiência, tipo de } \\
\text { parceria pretendida e disponibilidades internas como conhecimentos, habilidades e atitudes. } \\
74 \text { - Ao planejar uma ação de parceria, deve-se procurar conhecer igualmente os pontos } \\
\text { fortes e fracos da possível contraparte, no sentido de identificar sua viabilidade. } \\
75 \text { - A ação deve ser divulgada e institucionalizada perante os stakeholders. } \\
76 \text { - Em uma parceria estabelecida, as diferenças organizacionais devem ser expostas para } \\
\text { que possam ser discutidas e para que se evitem surpresas. } \\
77 \text { - Outro cuidado diz respeito à tendência de um parceiro atribuir ao outro a execução de } \\
\text { tarefas que não domina. } \\
78 \text { - A cultura dos parceiros deve ser levada em consideração na efetivação das parcerias. }\end{array}$ \\
\hline Queiroz (2010) & $\begin{array}{l}79 \text { - O Governo se utiliza do discurso de democratização e modernização para a } \\
\text { transferência das responsabilidades do mesmo para os governos locais e a indução de } \\
\text { parcerias com a iniciativa privada. } \\
80 \text { - As parcerias são dadas como novas políticas públicas no novo contexto social, político } \\
\text { e econômico do Brasil, a partir dos anos } 1990 \text {. } \\
81 \text { - Para o Governo as parcerias com o setor privado são consideradas de extrema } \\
\text { importância para o novo modelo de financiamento do desenvolvimento. } \\
82 \text { - O movimento de parcerias traz muitas implicações para a democracia, pois ocorrem } \\
\text { perdas dos direitos materializados em políticas. }\end{array}$ \\
\hline
\end{tabular}

Fonte: Elaborado pelos autores com base na revisão bibliográfica.

Conforme se pôde perceber, vários autores utilizaram dos estudos sobre parcerias e contribuíram para o Terceiro Setor. Verifica-se também, que as contribuições possuem pontos em comum, os quais serão posteriormente categorizados. Por se tratarem de estudos realizados com metodologias diferentes, realizados em locais diferentes e por pessoas diferentes, considerou-se relevante buscar contribuições internacionais.

No Quadro 3 podem-se verificar os estudos internacionais analisados, dos quais se retirou as contribuições práticas às instituições do Terceiro Setor:

\section{Quadro 3 - Trabalhos internacionais analisados e suas contribuições ao Terceiro Setor}

\begin{tabular}{|c|c|}
\hline Autores & Demais Informações \\
\hline \multicolumn{2}{|r|}{$\begin{array}{ll}\text { Periódicos } \\
\end{array}$} \\
\hline Couto (2001) & $\begin{array}{l}83 \text { - A campanha "YES" sugere algumas generalizações a respeito de organizações do } \\
\text { Terceiro Setor que buscam a promoção da sociedade civil diretamente e intencionalmente, } \\
\text { tais como: a liderança emergiu da rede formal e profissional do Terceiro Setor e demonstrou } \\
\text { as habilidades políticas latentes adquiridas; } \\
84 \text { - A campanha "YES" demonstrou a capacidade das organizações do Terceiro Setor para } \\
\text { mobilizar recursos e redes para melhorar a sociedade civil. }\end{array}$ \\
\hline $\begin{array}{l}\text { Ranci, } \\
\text { Pellegrino e } \\
\text { Pavolini } \\
(2005) \\
\end{array}$ & $\begin{array}{l}85 \text { - O governo, a legislação e os aspectos culturais e ideológicos interferem na forma como } \\
\text { as organizações do Terceiro Setor se organizam. } \\
86 \text { - Os resultados alcançados pelas organizações do Terceiro Setor refletem diretamente em } \\
\text { seu reconhecimento e legitimação. }\end{array}$ \\
\hline $\begin{array}{c}\text { Goddard } \\
(2006)\end{array}$ & $\begin{array}{l}87 \text { - As variadas formas de se estabelecer parcerias sugerem que é necessário um novo } \\
\text { modelo de trabalho para orientar sua implementação e gestão. } \\
88 \text { - As parcerias, incentivadas e preferidas pelo governo, são mais que simples retórica, pois } \\
\text { apesar dos problemas enfrentados conseguem encontrar soluções inovadoras. }\end{array}$ \\
\hline
\end{tabular}




\begin{tabular}{|c|c|}
\hline Autores & Demais Informações \\
\hline \multicolumn{2}{|r|}{ Periódicos } \\
\hline $\begin{array}{l}\text { Macken-Walsh } \\
\quad(2006)\end{array}$ & $\begin{array}{l}89 \text { - Experiências coletivas anteriores (pré-socialismo e socialismo, no caso estudado) } \\
\text { facilitam o desenvolvimento das organizações do Terceiro Setor. } \\
90 \text { - A ausência de elitismo e as diferenças de classe fortalecem as bases para a colaboração. }\end{array}$ \\
\hline $\begin{array}{l}\text { Carmel e } \\
\text { Harlock } \\
(2008)\end{array}$ & $\begin{array}{l}91 \text { - Descreve propostas recentes para as parcerias entre o Terceiro Setor e o Setor Público, } \\
\text { baseadas na lógica do mercado. }\end{array}$ \\
\hline $\begin{array}{l}\text { Milbourne } \\
\quad(2009)\end{array}$ & $\begin{array}{l}92 \text { - As mudanças na forma de relacionamento entre o Terceiro Setor e o Estado apesar de } \\
\text { buscarem uma forma mais eficiente de utilização dos recursos, gera prejuízos à natureza do } \\
\text { trabalho das organizações de pequeno porte do Terceiro Setor, que perdem seu potencial de } \\
\text { ação local. }\end{array}$ \\
\hline \multicolumn{2}{|r|}{ Congressos, Seminários e Afins } \\
\hline $\begin{array}{l}\text { Hall, Hall e } \\
\text { Lockley } \\
\text { (2000) }\end{array}$ & $\begin{array}{l}93 \text { - Foi identificada uma tendência de maior formalização do sistema de gestão no Terceiro } \\
\text { Setor. } \\
94 \text { - As organizações do Terceiro Setor acreditam na prestação de serviços pelas } \\
\text { universidades e percebem os benefícios da parceria. } \\
95 \text { - Os projetos de parceria desta natureza devem envolver todos os stakeholders e não } \\
\text { apenas os gestores. }\end{array}$ \\
\hline $\begin{array}{l}\text { Hsu e Liao } \\
\quad(2006)\end{array}$ & $\begin{array}{l}96 \text { - O Terceiro Setor pode atuar como fiscalizador das parcerias estabelecidas entre o } \\
\text { público e o privado. }\end{array}$ \\
\hline \multicolumn{2}{|r|}{ Dissertações } \\
\hline $\begin{array}{l}\text { Olivotto } \\
(2010)\end{array}$ & $\begin{array}{l}97 \text { - O estudo sugere que há uma ligação entre os sintomas ligados à cultura organizacional e } \\
\text { que a melhor maneira de intervir é atuando nas causas raízes e não em tais sintomas. Sugere } \\
\text { também que se deve promover uma cultura comum para minimizar o espaço de conflitos } \\
\text { entre os stakeholders e prevenir o colapso da parceria. }\end{array}$ \\
\hline
\end{tabular}

Fonte: Elaborado pelos autores com base na revisão bibliográfica.

Conforme se pôde perceber, vários autores internacionais, de vários países, também realizaram estudos acerca das parcerias; mesmo em realidades e culturas diferentes alguns pontos podem ser considerados comuns, passíveis de categorização, junto aos estudos brasileiros.

\subsection{Criação das categorias de análise}

Mediante as contribuições obtidas e seus pontos considerados comuns aos estudos, providenciou-se a separação dos resultados em categorias, as quais seguem no Quadro 4, no qual é possível identificar os autores, as categorias e as explicações: 
Quadro 4 - Categorias criadas para facilitar a análise dos dados

\begin{tabular}{|c|c|c|c|}
\hline Categorias & Autores & $\begin{array}{l}\text { Número da } \\
\text { Contribuição }\end{array}$ & Explicações \\
\hline OPORTUNIDADES & $\begin{array}{l}\text { Garcia e Sales (1999); Fernandes } \\
\text { (2004); Monte e Carvalho (2005); } \\
\text { Peroni et al. (2009); Almeida e Praça } \\
\text { (2009); Silva et al. (2009); Lopes e } \\
\text { Baldi (2009); Gorni, Dreher e Machado } \\
\text { (2009); Godói-de-Sousa e Valadão } \\
\text { Júnior (2011); Fischer e Falconer } \\
\text { (1998); Gutierrez (2007); Perret et al. } \\
\text { (2009); Carvalho (2010); Queiroz } \\
\text { (2010); Couto (2001); Goddard (2006); } \\
\text { Hall, Hall e Lockley (2000); Hsu e Liao } \\
\text { (2006); Ranci, Pellegrino e Pavolini } \\
\text { (2005); Macken-Walsh (2006); Carmel e } \\
\text { Harlock (2008). }\end{array}$ & $\begin{array}{c}1,3,5,6,12,13, \\
17,18,20,23,27, \\
28,29,30,34,35, \\
43,45,47,49,50, \\
53,55,56,57,59 \\
61,70,71,80,81, \\
83,84,86,88,89, \\
90,91,94,96 .\end{array}$ & $\begin{array}{l}\text { Oportunidades que } \\
\text { podem ser } \\
\text { observadas para a } \\
\text { realização das } \\
\text { parcerias. }\end{array}$ \\
\hline DESAFIOS & $\begin{array}{l}\text { Garcia e Sales (1999); Fernandes } \\
\text { (2004); Monte e Carvalho (2005); } \\
\text { Kniphoff, Nazzari e Oliveira (2006); } \\
\text { Lopes e Baldi (2009); Gorni, Dreher e } \\
\text { Machado (2009); Lima e Filho (2010); } \\
\text { Godói-de-Sousa e Valadão Júnior } \\
\text { (2011); Perret et al. (2009); Carvalho } \\
\text { (2010); Ranci, Pellegrino e Pavolini } \\
\text { (2005); Goddard (2006); Hall, Hall e } \\
\text { Lockley (2000); Olivotto (2010). }\end{array}$ & $\begin{array}{c}2,4,11,16,19,31, \\
36,37,38,39,40, \\
41,42,44,46,48, \\
51,52,60,62,64, \\
73,74,75,76,77, \\
78,85,87,93,95, \\
97 .\end{array}$ & $\begin{array}{l}\text { Procedimentos que, } \\
\text { se seguidos, } \\
\text { providenciarão } \\
\text { maiores chances de } \\
\text { sucesso às parcerias, } \\
\text { porém, são } \\
\text { desafiantes. }\end{array}$ \\
\hline CRÍTICAS & $\begin{array}{l}\text { Fernandes (2004); Monte e Carvalho } \\
\text { (2005); Peroni et al. (2009); Queiroz } \\
\text { (2010); Milbourne (2009). }\end{array}$ & $\begin{array}{l}8,15,21,22,24 \\
25,26,79,82,92 .\end{array}$ & $\begin{array}{l}\text { Pontos nos quais as } \\
\text { parcerias, } \\
\text { teoricamente, seriam } \\
\text { ruins a, ao menos, } \\
\text { um dos parceiros. }\end{array}$ \\
\hline CIDADÃS & $\begin{array}{l}\text { Oliveira e Engler (2009); Perret et al. } \\
\text { (2009); Stefani et al. (2012). }\end{array}$ & $\begin{array}{l}32,33,58,63,65 \\
\quad 66,67,68,69 . \\
\end{array}$ & $\begin{array}{c}\text { Ações que } \\
\text { promovem cidadania. }\end{array}$ \\
\hline LEGAIS & Fernandes (2004); Gutierres (2007). & $7,9,10,54$ & $\begin{array}{l}\text { Implicações jurídicas } \\
\text { das parcerias do } \\
\text { Terceiro Setor. }\end{array}$ \\
\hline ECONÔMICAS & $\begin{array}{l}\text { Monte e Carvalho (2005); Carvalho } \\
(2010) \text {. }\end{array}$ & 14,72 . & $\begin{array}{l}\text { Ações que envolvem } \\
\text { questões financeiras. }\end{array}$ \\
\hline
\end{tabular}

Fonte: Elaborado pelos autores com base na revisão bibliográfica.

A categoria Oportunidades teve a maior concentração de autores (21) e a maior quantidade de contribuições (40). Isso mostra como os estudos foram pautados em promover as parcerias como estratégia de condução da organização. A categoria Desafios também foi bastante observada por muitos autores (14) e também recebeu muitas contribuições (32), seguidas pela categoria Críticas, que obteve 5 autores e 10 contribuições.

Foram observadas, também, categorias menos presentes, tais como as Legais e as Econômicas, ambas com apenas 2 autores. Isso pode mostrar a preocupação dos autores em mudar o foco de estudo, de mera questão econômica para as questões cidadãs, sem menosprezar a necessidade de estabelecer-se a legalidade dos atos.

\subsection{Sugestões aos gestores de empreendimentos sociais}

Após todas as informações coletadas nos diversos estudos realizados e categorização das mesmas, seguem, no Quadro 5, sugestões aos gestores de empreendimentos sociais, a fim de sanar problemas e englobar o maior número de contribuições expostas pelos autores: 
Quadro 5 - Sugestões aos gestores de Organizações do Terceiro Setor

\begin{tabular}{|c|c|l|}
\hline $\mathbf{N}^{\mathbf{0}}$ & Categorias & \multicolumn{1}{c|}{ Sugestões } \\
\hline 1 & OPORTUNIDADES & $\begin{array}{l}\text { Uma vez preparados e cientes dos acontecimentos, os gestores sociais estarão } \\
\text { aptos a perceber as oportunidades que surgirão e deverão ser aproveitadas } \\
\text { maximizando as chances de sucesso e sobrevivência da organização; essas } \\
\text { oportunidades de parcerias podem ser verificadas em relação aos três setores. }\end{array}$ \\
\hline 2 & $\begin{array}{l}\text { Devem-se observar atentamente as contribuições dos autores quanto aos desafios, } \\
\text { uma vez que, caso sejam superados, trarão sucesso, mas caso sejam perdidos, } \\
\text { poderão trazer malefícios à organização; é preciso ter bastante cautela quando do } \\
\text { estabelecimento de parcerias, principalmente em relação à missão e objetivos } \\
\text { organizacionais. }\end{array}$ \\
\hline 3 & CRÍTICAS & $\begin{array}{l}\text { Não existem apenas fatores positivos no estabelecimento de parcerias; existem } \\
\text { diversos entraves para a formalização das parcerias e estes devem ser } \\
\text { amplamente conhecidos pelos gestores sociais a fim de se evitar surpresas } \\
\text { desagradáveis. }\end{array}$ \\
\hline 5 & CIDADÃS & $\begin{array}{l}\text { Sugere-se aos gestores que não se esqueçam da principal razão da existência da } \\
\text { organização, a fim de não permitir que o foco da ação social seja desviado por } \\
\text { questôes políticas ou interesses pessoais. }\end{array}$ \\
\hline 6 & ECONÔMICAS & $\begin{array}{l}\text { O atendimento a todas as legislações faz-se necessário em qualquer que seja a a } \\
\text { parceria; assim, com um grande conhecimento dos procedimentos, direitos e } \\
\text { deveres das parcerias, se terá uma maior chance de sucesso. }\end{array}$ \\
\hline $\begin{array}{l}\text { Parcerias econômicas, nas quais as organizações recebem recursos para efetivar } \\
\text { projetos, são muito bem-vindas, porém, devem ser controladas ativamente pela } \\
\text { organização e dada a devida transparência quanto à aplicabilidade dos recursos. }\end{array}$ \\
\hline
\end{tabular}

Fonte: Elaborado pelos autores com base na revisão bibliográfica.

Conforme se percebe, as sugestões estão alinhadas às categorias outrora estabelecidas, as quais também foram baseadas nas contribuições elencadas nos estudos. Com essas sugestões espera-se colaborar para uma melhora na gestão das parcerias referentes ao Terceiro Setor.

\subsection{Parâmetros de análise de parcerias do terceiro setor}

Após a coleta de todas as informações do estudo, propõem-se parâmetros apresentados na Figura 2, abaixo, os quais podem ser utilizados para o entendimento das novas relações entre os parceiros com as organizações do Terceiro Setor. 


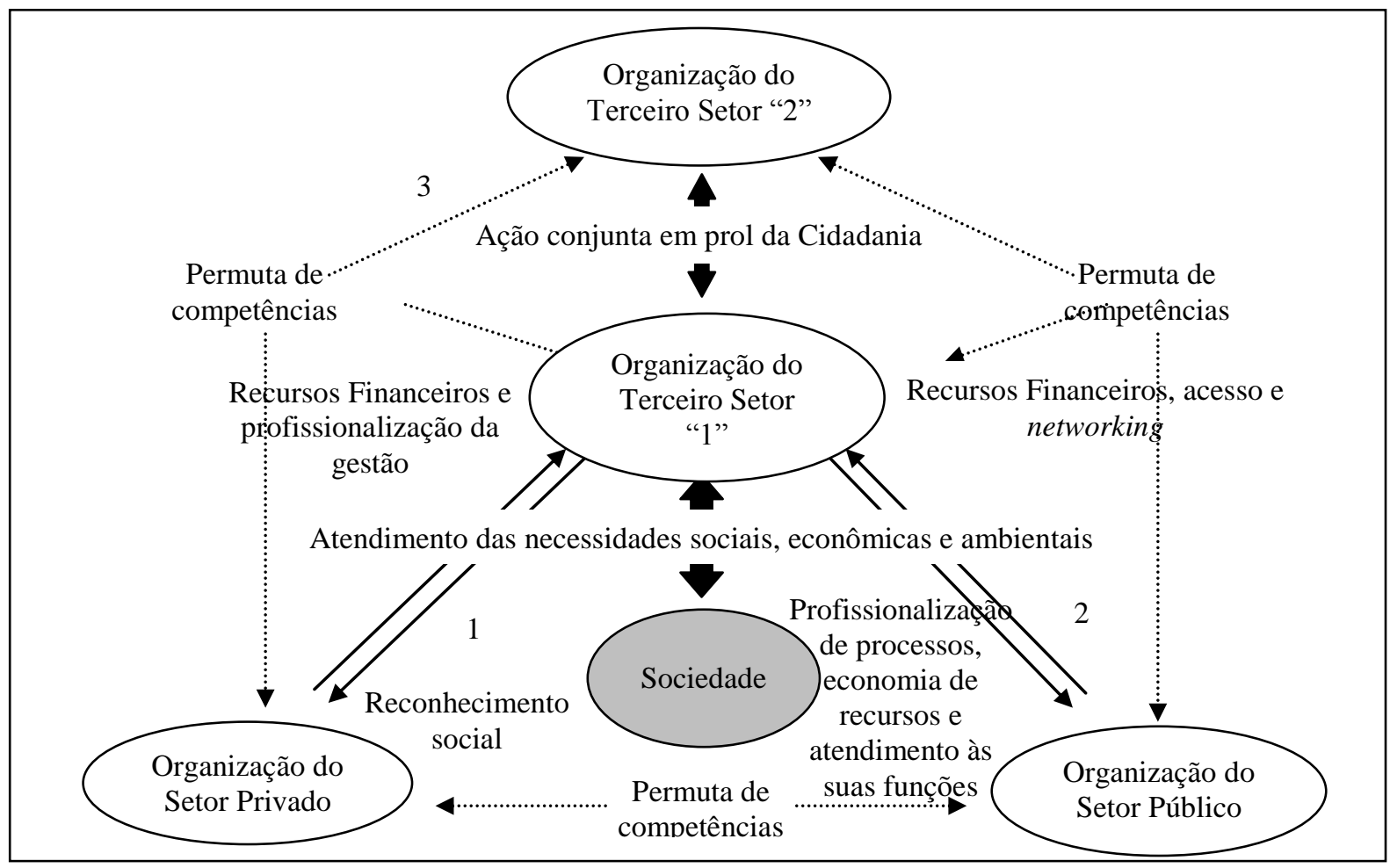

Figura 2 - Proposta de parâmetros de análise de parcerias do Terceiro Setor.

Fonte: Elaborada pelos autores.

Nesses parâmetros é possível observar as relações entre os três setores, definidas e esquematizadas como as pontas de um triângulo: governo, organizações privadas e as organizações sociais; neste mesmo cenário, a sociedade é colocada ao centro deste triângulo de relações, uma vez que todos os serviços a serem prestados, por todas as três entidades, em tese, seriam para seu atendimento. Na primeira relação (1), entre as organizações privadas e as organizações do Terceiro Setor, a parceria promove o reconhecimento da sociedade e a legitimidade da empresa como Cidadã (MONTE; CARVALHO, 2005); promove às organizações do Terceiro Setor o acesso aos recursos financeiros e à profissionalização da gestão. Na segunda relação (2), entre as organizações pertencentes ao setor público e as organizações do Terceiro Setor, a parceria promove a Prestação dos Serviços Públicos (GODÓI-DE-SOUSA; VALADÃO JÚNIOR, 2011), ou seja, aqueles que já deveriam estar sendo realizados pelo próprio estado, mas que o mesmo é incompetente no ato (FISCHER; FALCONER, 1998); dessa forma o governo, além de cumprir com o seu papel, consegue economizar recursos e profissionalizar seus processos (GUTIERRES, 2007); esta mesma relação promove às organizações do Terceiro Setor a entrada de recursos que poderão subsidiar a sua sobrevivência, acesso a pessoas, empresas e informações importantes para a prestação de serviços à comunidade e o aumento do networking. Na terceira possibilidade de relação (3), as parcerias entre organizações do Terceiro Setor, impactarão no desenvolvimento de atividades sociais em prol do atendimento das necessidades da sociedade (OLIVEIRA; ENGLER, 2009) e a melhora das questões gerenciais, por intermédio de cooperação e de benefícios mútuos (MONTE; CARVALHO, 2005). Permeando todas as relações entre os três setores, há a permuta de competências, uma vez que a experiência de operação, gestão e diversidade de informações acabam por favorecer a troca de conhecimentos. 
Esta proposta, para ajudar a entender os procedimentos de parcerias contemporâneas, tem a intenção de agregar maiores informações às já existentes e levá-las ao encontro com as verificações e constatações da atualidade.

\section{CONSIDERAÇÕES FINAIS}

Este artigo teve o objetivo de levantar, entender e categorizar as principais contribuições dos estudos já realizados, sugerir ações aos gestores e propor parâmetros de análise para exemplificar a atualidade.

Conseguiu-se expor 97 contribuições práticas dos trabalhos já realizados, acerca de parcerias no Terceiro Setor, em formato de dois quadros, um apenas com estudos nacionais e outro apenas com estudos internacionais. As contribuições foram separadas e categorizadas, de maneira a facilitar o entendimento das mesmas e esquematizar quais são os pontos que necessitam de maior atenção. Dentre essas categorias, de um total de seis, pode-se citar, principalmente, contribuições relativas às Oportunidades das ações de parceria, aos Desafios e às Críticas. Com base nessas informações foram sugeridas seis ações aos gestores sociais, uma para cada categoria feita, para que consigam prover uma melhor administração de suas instituições e foram propostos parâmetros, aqui denominados Parâmetros de Análise Contemporâneos de Parcerias do Terceiro Setor.

Nestes, percebeu-se que a maioria dos trabalhos estudados chegou a conclusões positivas acerca das parcerias; alguns poucos, porém, citaram e expuseram fatores negativos de forma a diminuir sua importância. Como conclusão, acredita-se que as parcerias podem ser positivas para todos os envolvidos, se efetivadas conforme sugestões, e negativas, caso não se leve em consideração todos os aspectos necessários e citados em toda a revisão realizada.

Com este trabalho pretendeu-se colaborar com a academia com a revisão de estudos referentes ao Terceiro Setor, mais especificamente em relação às parcerias, de forma a organizar o que já foi estudado, discutido e explicitado e propor parâmetros de análise de parceria contemporâneos. Pretendeu-se auxiliar as instituições deste setor a utilizarem tais contribuições verificadas e sugestões postas, a fim de facilitar e/ou melhorar o processo de gestão com consequente ampliação da capacidade de sobrevivência das organizações. Dessa forma, este estudo busca atendar às necessidades da sociedade em geral, uma vez que, conforme Calegare e Silva Júnior (2009), essas são instituições criadas por cidadãos em prol do desenvolvimento e dignidade da própria sociedade.

Como recomendações futuras sugerem-se novas revisões bibliográficas acerca de parcerias, utilizando outras palavras-chave como busca, a fim de comparar os resultados das contribuições observados e posteriores categorias. Indica-se, também, a aplicação das sugestões outrora postas, com posterior verificação dos resultados de seus usos, a fim de observar sua eficácia. Recomenda-se, ainda, a aplicação de questionários e realização de entrevistas com gestores sociais, acerca dos novos parâmetros de análise propostos, a fim de comprovar ou refutar a fidedignidade das informações nele atribuídas. 


\section{REFERÊNCIAS}

ALMEIDA, J. M. de; PRAÇA, N. de S. Transmissão vertical zero: parceria entre o serviço público e o terceiro setor. Acta Paulista de Enfermagem, São Paulo, v.22, n.4, p. 374-379, 2009.

BARROS, A. J. S.; LEHFELD, N. A. S. Fundamentos de metodologia: um guia para a iniciação científica. 2. ed. São Paulo: Makron Books, 2000.

BAUER, M. W.; GASKELL, G. (Orgs.). Pesquisa qualitativa com texto, imagem e som: um manual prático. 9. ed. Petrópolis: Editora Vozes, 2011.

BOSE, M.; GODÓI-DE-SOUSA, E. Empreendedorismo Social e Desenvolvimento Social: Desafios e Oportunidades. In: VI ENCONTRO NACIONAL DE PESQUISADORES EM GESTÃO SOCIAL - ENAPEGS, 2012, São Paulo. Anais... São Paulo: 18 f., 2012.

BRONZO, C.; TEODÓSIO, A. S. S.; ROCHA, M. C. G. da. Tri-sector partnerships in social entrepreneurship: discourse and practice of the actors from the circles of action and reflection. Revista de Administração, São Paulo, v.47, n.3, p. 446-460, jul./ago./set. 2012.

CALEGARE, M. G. A.; SILVA JÚNIOR, N. A "construção" do terceiro setor no Brasil: da questão social à organizacional. Psicologia Política, v.9, n.7, p. 129-148, jan./jun. 2009.

CARMEL, E.; HARLOCK, J. Instituting the "third sector" as a governable terrain: partnership, procurement and performance in the UK. Policy \& Polites, v.36, n.2, p. 155-71, 2008.

CARVALHO, F. F. V. Expansão territorial de um programa de microcrédito por meio de parceria estado-terceiro setor: o caso viva cred-crediamigo. 2010. 146 f. Dissertação (Mestrado em Gestão Empresarial)-Escola Brasileira de Administração Pública e de Empresas, Fundação Getúlio Vargas, Rio de Janeiro, 2010.

COUTO, R. A. The third sector and civil society: the case of the "YES" campaign in Northen Ireland. VOLUNTAS: International Journal of Voluntary and Nonprofit Organizations. v.12, n.3, Sep. 2001.

FERNANDES, L. de M. Subsidiariedade e parceria: o terceiro setor (as organizações da sociedade civil). Revista Esmafe: Escola da Magistratura Federal, Recife, n.6, p. 269-339, abr. 2004.

FISCHER, R. M.; FALCONER, A. P. Desafios da parceria governo terceiro setor. In: PRIMEIRO ENCONTRO DA REDE DE PESQUISAS SOBRE O TERCEIRO SETOR NA AMÉRICA LATINA E CARIBE - ISTR. Anais... 11 f., 1998.

GARCIA, M. V.; SALES, R. O papel da escola de governo na construção de uma nova relação entre estado e terceiro setor: da desconfiança à parceria. Revista Paranaense de Desenvolvimento, Curitiba, n.96, p. 77-89, maio/ago. 1999.

GIL, A. C. Como elaborar projetos de pesquisa. 5. ed. São Paulo: Atlas, 2007. 
GODDARD, J. Third Sector in Partnership Arrangements: Navigating New Waters or Treading Water? In: THE AUSTRALIA AND NEW ZEALAND THIRD SECTOR RESEARCH EIGHTH CONFERENCE, Adelaide, Australia. Anais... p. 26-28. nov. 2006.

GODÓI-DE-SOUSA, E. Redes organizacionais: uma perspectiva para a sustentabilidade de uma ONG em Uberlândia-MG. 2005. 232 f. Dissertação (Mestrado)-Universidade Federal de Uberlândia, 2005.

GODÓI-DE-SOUSA, E.; VALADÃO JÚNIOR, V. M. As formas, a natureza e os tipos de articulações da aliança entre ONG e o governo - Um estudo de caso. Interface, Natal, v.8, n.2, jul./dez. 2011.

GORNI, P. M.; DREHER, M. T.; MACHADO, D. D. P. N. Parceria e cooperação intersetorial em uma organização do terceiro setor: o caso do Balneário Camboriú com Vida Convention \& Visitors Bureau. Revista Turismo Visão e Ação, v.11, n.2, p. 263-279, maio/ago. 2009.

GUTIERRES, D. V. G. A descentralização da gestão pública no Brasil e o terceiro setor: a gestão da educação no município de Altamira/PA em parceria com o Instituto Ayrton Senna. In: XXIII SIMPÓSIO BRASILEIRO - ANPAE. Anais... 20 f. 2007.

HALL, D.; HALL, I.; LOCKLEY, S. Third sector/university partnership: developing research as community resource. In: FOURTH INTERNATIONAL CONFERENCE OF THE INTERNATIONAL SOCIETY FOR THIRD-SECTOR RESEARCH (ISTR), Dublin, Ireland. Anais... Jul. 5-8, 2000.

HSU, S.; LIAO, G. L. Privatization, Partnership Planning and the Exclusion of Citizens Role of the Third Sector to Take in Taiwan. In: $7^{\mathrm{TH}}$ INTERNATIONAL CONFERENCE OF THE INTERNATIONAL SOCIETY FOR THIRD-SECTOR RESEARCH (ISTR). Bangkok, Thailand. Anais... Jul. 9-12, 2006.

JUNQUEIRA, L. A. P. Gestão Social: organização, parceria e redes sociais. In: CANÇADO, A.; TORRES SILVA, J.; SHOMMER, P.; RIGO, A. (ORG.) Os desafios da formação em gestão social. Palmas: Provisão, 2008, v. 02, p. 87-103.

KNIPHOFF, D. T.; NAZZARI, M. T.; OLIVEIRA, M. V. de. Terceiro Setor e inclusão social: o caso da OSCIP nova aliança no oeste do Paraná. Ciências Sociais em Perspectiva, Cascavel, v.5, n.9, p. 95-108, 2006.

LIMA FILHO, R. N. Auditoria independente nos contratos de parceria em entidades do terceiro setor à luz da lei 9.790/99. ReAC - Revista de Administração e Contabilidade, Feira de Santana, v.2, n.1, p. 15-27, jan./jun. 2010.

LOPES, F. D.; BALDI, M. Redes como perspectiva de análise e como estrutura de governança: uma análise das diferentes contribuições. Revista de Administração Pública RAP, Rio de Janeiro, v.43, n.5, p. 1007-1035, set./out. 2009.

MACKEN-WALSH, A. Community Action in post-socialist Lithuania: third sector participation in a rural partnership programme. The Rural Economy Research Centre Working Papers Series. Working Paper, 06-WP-RE-20. March, 2006. 
MARTINHO, C. Algumas palavras sobre rede. In: SILVEIRA, C. M.; COSTA REIS, L. da (orgs.). Desenvolvimento local, dinâmicas e estratégias. Rede DLIS/RITS, 2001.

MILBOURNE, L. Remodeling the third sector: advancing collaboration or competition in community based initiatives? Journal of Social Policy, v.38, n.2, p. 277-297, Abr., 2009.

MONTE, T.; CARVALHO, C. A. Poder e relações de parceria no terceiro setor. Revista de Ciências da Administração, v.7, n.14, jul./dez. 2005.

OLIVEIRA, E. M. Empreendedorismo social no Brasil: atual configuração, perspectivas e desafios-notas introdutórias. Revista da FAE, v. 7, n. 2, 2016.

OLIVEIRA, L.; ENGLER, H. B. R. Parceria entre estado e terceiro setor: uma alternativa no enfrentamento das questões sociais. Serviço Social \& Realidade, Franca, v.18, n.1, p. 277$299,2009$.

OLIVOTTO, V. The impact $\mathbf{f}$ organizational culture and balance of power on a publicthird sector partnership (PTSP). 2010. Dissertação (Mestrado) - Lund University, Rotterdan, 2010.

PERONI, V. M. V. et al. Terceira via, terceiro setor e a parceria IAS/sistemas de ensino público no Brasil. Educação: Teoria e Prática, v.19, n.32, p. 17-35, jan./jun. 2009.

PERRET, N. et al. Gestão de parcerias e redes sociais: em busca da gestão social eficaz. In: XII SEMEAD - EMPREENDEDORISMO E INOVAÇÃO. Anais... 15 f, 2009.

PRATES, A. A. P. Redes sociais em comunidades de baixa renda: os efeitos diferenciais dos laços fracos e dos laços fortes. RAP, Rio de Janeiro, v.43, n.5, p.1117-1146, SET./OUT. 2009.

QUEIROZ, R. S. do N. O papel do terceiro setor nas políticas públicas a partir dos anos 1990 no Brasil: Análise da Parceria Instituto Ayrton Senna e SEDUC-TO na Oferta de Programas Se Liga e Acelera Brasil (2004-2009), 2010. 138 f. Dissertação (Mestrado)Universidade Federal de Goiás, 2010.

RANCI, C.; PELLEGRINO, M.; PAVOLINI, E. The third sector and the policy process in Italy: between mutual accommodation and new forms of partnership. Third Sector European Policy Working Papers. n.4, Jun. 2005.

SILVA, G. M. et al. Empreendedorismo no terceiro setor: redes sociais e cadeias produtivas de material reciclável. Revista da Micro e Pequena Empresa, Campo Limpo Paulista, v.2, n.3, p. 80-94, 2009.

STEFANI, M. T. et al. Redes sociais e a produção acadêmica nas principais revistas brasileiras de administração no período de 2001 até 2011. In: VI ENCONTRO NACIONAL DE PESQUISADORES EM GESTÃO SOCIAL - ENAPEGS. Anais... 20 f., 2012. 
TESCHE, R. W. As relações de reciprocidade dos agricultores familiares e a formação de redes de cooperação no noroeste do Rio Grande do Sul. Sober, 1999. Disponível em: <http://www.cnpta.embrapa.br/sbsp/anais/resumos_trab/40.htm>. Acesso em: 22 out. 2012.

THOMPSON, A. A. Do compromisso à eficiência? Os caminhos do terceiro setor na América Latina. In: IOSCHPE, Evelyn (Org.). $3^{\circ}$ Setor - desenvolvimento social sustentado. São Paulo: Paz e Terra, 1997, p.41-48.

VERGARA, S. C. Projetos e relatórios de pesquisa em administração. São Paulo: Atlas, 2005. 